be, there is no violation of the fundamental law of modern physics, - no destruction of energy.

The second practical problem is to cover as large a surface as possible with the viscous fluid. Fortunately this can be done easily in accordance with principles explained in many modern treatises on capillarity : for the surface tension of the film between water and air is so much greater than the sum of the tensions, oil-water and oil-air, that a drop of oil is very rapidly drawn out over an enormous surface. If this paper were not already so long, some numerical data might be given. The preference shown for animal or vegetable oils over mineral oils (Science, vii. 133) is probably justified by the smaller surface tension and greater viscosity of the former; though it may be noted, that, the greater the viscosity, the slower the oil will spread, other things remaining the same.

To render complete the explanation of this interesting and at first sight puzzling action of oil, experiments are needed by physicists in the laboratory, where for various oils the several physical properties above named shall be measured, and also experiments and observations at sea when wind and waves are moderate enough to be measured, and the captain may go in any desired direction without danger. A few days' observations, where the conditions can be controlled, would be worth hundreds of the desultory reports which the hydrographic office is wisely collecting. Charles K. Wead.

\section{Professor Thorell and the American Silurian scorpion.}

Professor Thorell, who is perhaps the best authority upon the Scorpionidae, both recent and fossil, has rather severely taken to task some of my statements and determinations in connection with the recently discovered American Silurian scorpion (see American naturalist for March, 1886, p. 269). In fact, so sharp and pungent are some of his remarks, that a person reading them would naturally infer, that, in Professor Thorell's opinion, I was hardly capable of making a reliable observation, at least not upon a scorpion. He has shown his good nature, however, in the outstart, by admitting that the specimen is really a scorpion, and not a Eurypteroid, - a conclusion the exact contrary of that jumped to by one critic upon reading the first announcement of its discovery. For this concession Professor Thorell has my heartiest thanks. In his further criticisms, however, he is much less lenient, and I wish to briefly notice his objections in their order.

After making the above-mentioned admission, Professor Thorell proceeds to deal with the six ventral plates of this, what he calls, ' rather badly preserved fossil.' In my description in the American museum bulletin, I mention that the specimen is 'greatly compressed;' that the 'dorsal crust is preserved over abont two-thirds of the surface,' mentioning the parts; and that "over the rest of the prae-abdomen and what remains of the post-abdomen or tail, parts of the first five segments, the inside of the ventral crust is exposed." This feature of the specimen has, I fear, misled Professor Thorell, and caused him to fall into an error, into which, if he had known the nature of the preservation of the fossils (Eurypteroids) found in the formations from which the scorpion was obtained, he probably would not have fallen. The specimen is greatly compressed vertically, as are all the fossils in the same rock. Along the left side of the abdomen there is a line of fracture, to the right of which the substance of the dorsal plates, and the filling between them, to the ventral plates below, has been removed in splitting the rock, and probably left on the other part. Along this line the thickness between the two sides of the fossil (dorsal and ventral) is about a twentieth of an inch or less. In speaking of this feature, Professor Thorell says, "The whole upper side of the abdomen is broken or cracked longitudinally," and that the articulations of the ventral parts are "all direct continuations of the articulations between the dorsals." Neither of these assertions is entirely true. The abdomen is partially removed, but not 'cracked" in the sense in which he uses the term; and the articulations between the joints of the ventral plates are not 'direct continuations' of those of the dorsal. Besides this, the overlapping of the plates show directly which is dorsal, and which is ventral; and no zoölogist would be apt to make the mistake. If we examine the abdomen of a beetle, roach, or scorpion, on the exterior, we find the anterior plates all overlapping those behind, both dorsally and ventrally: but, if we take off the crust and examine the inside, we find the reverse to be the case; that is, the anterior edge of the plates overlaps the one anterior to it. Now, this is precisely what is seen on this specimen : on the left side the anterior plates overlap those behind, while on the right side the posterior overlap those in front; and the surface of the plates is concave, while on the left side they are convex; so that a mistake is nearly impossible. Professor Thorell's statement, that, if his interpretation of this character is the right one, "the want of spiracles on the plates needs no furth'r explanation," is therefore of no value, as he reasons from false premises : all his conclusions based upon his assumed features fall to the ground, and the want of spiracles is yet unexplained. There are six of these ventral plates plainly seen, extending from beneath the dorsals. Neither is the specimen a 'rather badly preserved fossil,' but instead an exceedingly well preserved and distinct one, as far as the parts existed when the specimen was embedded.

In a footnote to his observations on the above structure, Professor Thorell states, that, "even if the plates in question really were ventral plates, the first (or sixth when counted from behind forward) would seem, from its position, to correspond to the anterior half of the first ventral in the ordinary scorpions, and not to the small plate situated between the pectoral combs." On this statement I will make no comment, further than to say that I have failed to find, in the living species which $I$ have examined, any case where the first (or anterior) ventral plate is even apparently articulated to the third ventral plate, or has the lateral width of this one.

Professor Thorell next goes on to say that "Mr. Whitfield thinks, that, whereas modern scorpions carry the tail (post-abdomen) arched upward over the back, Proscorpius, and also Palaeophonus, car. ried it in the opposite way, or curved downward." He says, "This would indeed be a character of fundamental importance for distinguishing the Silurion scorpions from all other members of the group," but that to him it is "impossible to find any strin. gent reason for adopting this strange hypothesis," and that it would cause "the animal's gait to be exceedingly difficult and awkward if it were to walk. 
with its tail curved under its body." I never intimated that it walked with its tail curved under its body; this is his own suggestion: but I rannot see why the animal might not walk with its tail straightened out behind, as well as to curve it over the back; in fact, the latter position seems much the more awkward of the two. As to stinging its prey after having caught it between the hands of its palpi, it might experience a little trouble : hence the necessity of the development of a more elevated feature by way of adaptation of parts to purposes. There must be a period in the life of a scorpion when the tail first assumes this elevated feature; for as Professor Thorell admits, just before birth in the living forms, the tail is curved downward. If the bend is downward then, when is it turned upward? and why, in these early forms, might not this embryonic feature be prolonged to a later or more advanced age Wasps and similar insects hend their bodies downward in stinging their prey, and are not particularly awkward, as I have often experienced. The ridges on the upper and lower surfaces of the tail-joints differ in all living scorpions which I have examined, and readily show which is dorsal, and which is ventral. Those seen on this specimen have the character of the ventral or lower side (inside as to curvature), and not "the same form and sculpture of the dorsal plates, or parts of these segments or joints in ordinary scorpions," as Professor Thorell wrongly asserts. They diverge at the anterior end, and converge at the posterior end. The very slight displacement of the tail segments is not sufficient to warrant the assumption that the entire tail has been turned over, although such may possibly be the case, but is not at all probable. I stated the fact of displacement in my description, and based my reasoning upon the improbability of its having been turned over. Of course, if it is turned over, my inferences are faulty. But has it been? I think not.

Professor Thorell next attacks the two poor little claws in the most pitiless manner, notwithstanding the animal has but one foot to show. This he holds out in the most appealing manner to the observer, entirely distinct, and free from interference by the other limbs, and with the two claws widely spread, as if in an effort to prevent disputation. Professor Thorell's remarks, in his effort to reason away one of these claws upon an assumption as to what a Silurian scorpion ought to be, partake so much of the character of 'special pleading,' that I do not feel called upon to make a very extended attempt at refutation. The specimen is so very distinct and positive in tbis respect, that I shall only say, in reply to Professor Thorell, that he can rest assured the specimen is not broken, or in any way mutilated in this part; that there are certainly two processes of almost equal size, the longer being only perceptibly narrower at its base, under a high magnification, than its mate; that the two processes are situated on the end of the joint behind, and not on the side of the end, in the position of a spine. Now, these processes he can call spines, or parts of a broken limb, or by any other name : they still remain claws to every appearance, are in the right position, and were undoubtedly used as such by the animal. In my examination of the specimen, I have made no assumption and manufactured no feature, simply taking the specimen as it is, without tinkering or dressing. I have had, in the matter of the double claw, the opinion, after examination, of many good observers, only one of whom failed to assert positively the existence of a double claw. That one exception, after a very cursory examination of only a very few minutes, gave no direct opinion.

After speaking of the transverse furrow across the base of the cephalothorax, Professor Thorell mentions 'the small size of the eyes' as a feature in which this specimen differs from the Eoscorpionidae, and states that "in this particular it more resembles Dr. Hunter's and Mr. Peach's Scotch Paleophonus." I am not aware that the eyes of Dr. Hunter's and Mr. Peach's Scotch Palaeophonus have been actually observed so as to know their exact size. The specimen lies with the ventral side up, the eyes being embedded in the rock below, but, according to $\mathrm{Mr}$. Peach, "are seen pressed up through the cuticle of the gullet," and would naturally appear somewhat larger than they really were in life, owing to the lifting of the cuticle over them. Consequently I do not see the force of the comparison.

Professor Thorell believes Proscorpius forms a ' good peculiar genus,' as " characterized by the somewhat trilobed anterior margin of the cephalothorax," - a feature which I should not consider as of more than specific value, - " and more especially by the shape of the fingers of the mandibles, which, if they really had such a form in the living animal as they, from Mr. Whitfield's figures, appear to have, differ materially from those of Palaeophonus and all other known scorpions." I am sorry Professor Thorell has not told us how they differ; then we should have had a basis of comparison. My figures of the mandible, three of which I gave, besides that in place on the enlarged figure in plate 19 (which, by the way, is not a drawing, but a print direct from a photograph of the specimen), were given to show the uncertainty of this part. They can bo verified, however, by reference to that figure.

As to Professor Thorell's opinion of the systematic position and relation of this American fossil scorpion, which he has based upon a lack of knowledge of the specimen, and the assumption of characters and faults which it does not possess, I shall say nothing, as it rests entirely on the existence of a single or double claw. But as to his "additional reason to those given above for removing Proscorpius from the carboniferous Eoscorpionidae, and for referring this genus to the Apoxypodes, fam. Palaeophonidae," which he says "may be found in its being, geologically speaking, almost contemporary with the Palaeophoni," I should object to make geological position even an 'additional reason' for zoölogical classification.

Regarding the aquatic nature of the animal, there can be no certainty. The apparent total absence of stigmata, vet unexplained. leads one to inquire how they breathed, even if aquatic. The same may be asked of its aquatic associates in the rock, Eurypterus and Pterygotus, which show neither stigmata nor branchiae; but their aquatic character is not questioned. That it should be any thing so "very strange,' that a connecting-link between a small and a large form, like the scorpion on the one hand, and the Pterygoti on the other, should be found in "such a little creature as the Proscorpius Osbornii," I think few will admit; nor are all the Eurypteri and Pterygoti so very 'gigantic' as his language would indicate.

R. P. WhitFIELd.

Amer. mus. nat. hist., New York City. 